\title{
SUSTAINABILITY OF HOUSING TYPOLOGIES IN HISTORIC SITES
}

\author{
ALEJANDRO ACOSTA COLLAZO \\ Autonomous University of Aguascalientes, Mexico
}

\begin{abstract}
Only few people in Mexico are researching about historic housing typologies. Architects, historic preservation scientists, urban planners and sociologists are basically the disciplines concerned about such topics. In addition, several researchers mention the importance of preserving industrial heritage, including houses of workers. But there are barriers to understand the importance of housing typologies in contemporary societies. The main goal of this paper is to analyse the people's points of view and to understand a social construction of industrial heritage; especially about those unique houses situated in historic sites, in order to understand meanings and how catalogued buildings are recognized. Also, housing typologies somehow impact society's perception on historic preservation. Besides, urban places affect how people feel. It is through the use of a survey and a questionnaire that cultural heritage sites can be analysed to know behaviours and opinions related to historic recognition and preservation facts. The objectives of the survey are to demonstrate the architectural influences from abroad in Mexican historic sites, also to find out about social interaction among workers and the administrators of the factories they work for, furthermore architecture and typology of buildings in company towns like Ferronales suburb, most common materials used in railway stations and company houses for workers, relevant land use changes in industrial sites and preservation concepts used in industrial heritage preservation. The questionnaire includes issues about preservation, comprising characteristics such as gender, age, educational level, origin, architectural concepts and urban facts, railway housing and local culture, meaning of historic sites, historic places and memories (breath of the places). Furthermore, a qualitative multivariate statistical method was used to enhance the conclusions. The results and conclusions include a typological analysis and the interpretation of social construction of industrial heritage sites.
\end{abstract}

Keywords: housing typologies, sustainability, industrial heritage, historic preservation.

\section{INTRODUCTION}

The company town concept was first used in England at the beginning of Industrial Revolution. The first factories needed a considerable number of workers and the best solution was to settle neighbourhoods closed to them. This idea allowed architects and designers to create several urban solutions to the company towns. So multiple designs appeared trying to solve the complex relationship between the factory and houses for workers. Designs depended on geographic location and types of factories. Some of the most important factories in Mexico - established during the 19th century - used to be textile factories. Such factories needed water flows in order to function properly. The current always varies spatially as well as the factories installed nearby.

Mills were built nearby or inside the factories using the streams to produce energy. Generators helped out to make the machines work in an efficient way so workers could produce, for example, wool and fabrics in textiles factories. So, the design of the factories depended on the natural site they were established at. This situation was relevant because specific sites also conditioned the factories, on the way they had to be built. This is also the case of construction materials. The usage of regional construction materials used to be a rule in architecture. Of course these phenomena changes, depending on time. But this theory is mentioned in this paper because regional materials ruled somehow building typologies, which is the main topic of this document. 
Some stone structures of factories appeared as a natural extension of the surroundings. Designs made with stone in factories produced a vertical shape of windows and main entrances at the beginning. This theory helps to understand housing typologies in historic sites. Besides, vertical windows were used to create pattern in multiple sites. After Industrial Revolution, the shapes of windows and entrances of buildings were still vertical. But slowly during the 20th century and modern movement, this situation changed. So, vertical windows tend to be related to historic buildings of a traditional shape and manufacture - and also to handmade buildings.

The created patterns in most of the company towns designs offer attractive landscape architecture. Sometime regional limestone was used as facing masonry in main buildings of company towns, but brick was the most common material in housing for workers in Mexico. In fact, aesthetics of historic sites have to do with historic patterns. Additionally, in order to study housing typologies in historic sites it is convenient to understand how people look at them. So, a survey and a questionnaire were applied to recognize social construction of industrial heritage.

\section{METHODOLOGY}

Historic sites usually comprise features that make them special, in aesthetic terms. There are several reasons to preserve a historic site. Among them, recognition of quality by users is an essential characteristic. How can such appreciation from people be documented? For example, the Latin American Tower has become a symbol in the historic centre of Mexico City for more than 60 years. People have learned to live with the presence of the tower that it feels like part of the urban context. Even though, it is situated among historic buildings and viceroyalty places. So, nowadays it is convenient to recognize that newer architecture integrates somehow with the past. This is related to what George Kubler mentioned as continuous change across time in The Shape of Time. He says: Calendrical time indicates nothing about the changing pace of events. The rate of change in history is not yet a matter for precise determinations: we will have advanced if only we arrive at a few ideas about the different kinds of duration [1]. In fact, no one would intend to demolish the Latin American Tower nowadays because it has become a symbol of Mexico City. This example also shows how postmodern architecture learned to incorporate itself within a historic site.

The first research instrument applied for this paper was a survey. It was implemented to 100 architecture students. The first question was: Under your point of view What is the main foreign architectural influence on industrial sites in Aguascalientes? The second item was: Explain briefly how social interaction was inside industrial heritage of Aguascalientes. The third item of the survey was: Can you identify architectural typologies of industrial heritage? The fourth item was: How do changes in land use impact industrial sites? And the fifth item was: Explain a relevant concept you know about industrial heritage.

The second research instrument gave consistent results from 5 inquirers, but some of the inquirer's results (one out of six inquirers) were not considered reliable. In the cases from the second to the sixth inquirers the results were validated and that included a total amount of 500 hundred inquiries. The inquiry forms were applied on line and sent by the inquirers' social media. A statistical mode was used to calculate the value that appeared most often:

$$
x(i . e, X=x)
$$

As we can observe in Fig. 1, from 500 questionnaires 100 were applied by each inquirer and subdivided into four groups. Subsequently, a statistical mode was used to obtain the number of respondents required for the Burt's matrix. The questions used by the inquirers included the following items: (1) Age of inquired people: Young (13-17), adults (18-60) 
and senior (+61). (2) Gender: Man or woman. (3) Educational level: Basic studies, graduate or post-graduate. (4) Origin: Mexican or foreigner. (5) Understanding the concept of industrial heritage. (6) Recognition of Ferronales suburb. (7) Preferences about Ferronales architecture: Wood windows, porches, tree lined streets or stone-paved streets. (8) Preferences about wood windows. (9) Value appreciation of: Ferronales suburb, Tres Centurias Park or the Mexican Smelting Co. Also, preferences about them: history, colours, successful companies or technology. (10) Contribution of industrial heritage to improve landscape architecture. (11) Memories (breath of the places) about Tres Centurias Park: trains, progress, pollution, manufacturing decline and significance of the place.
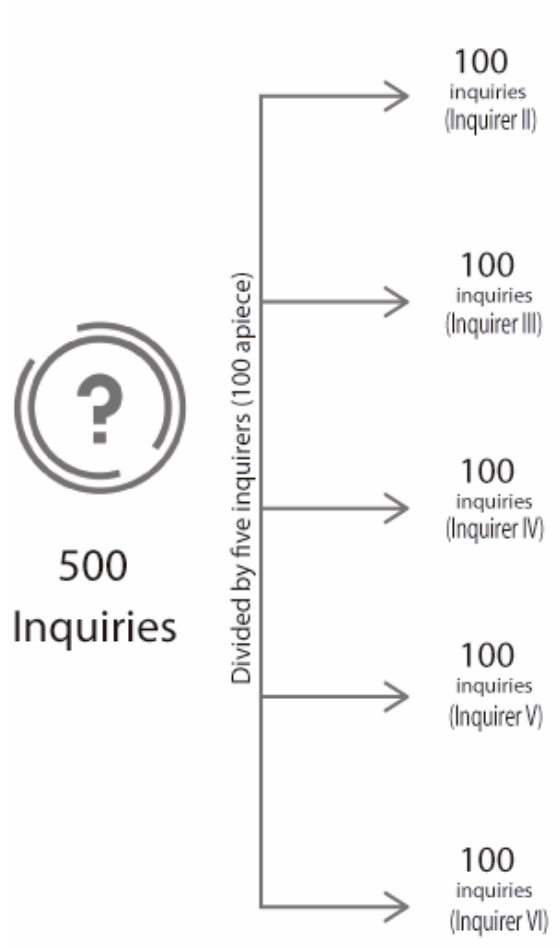
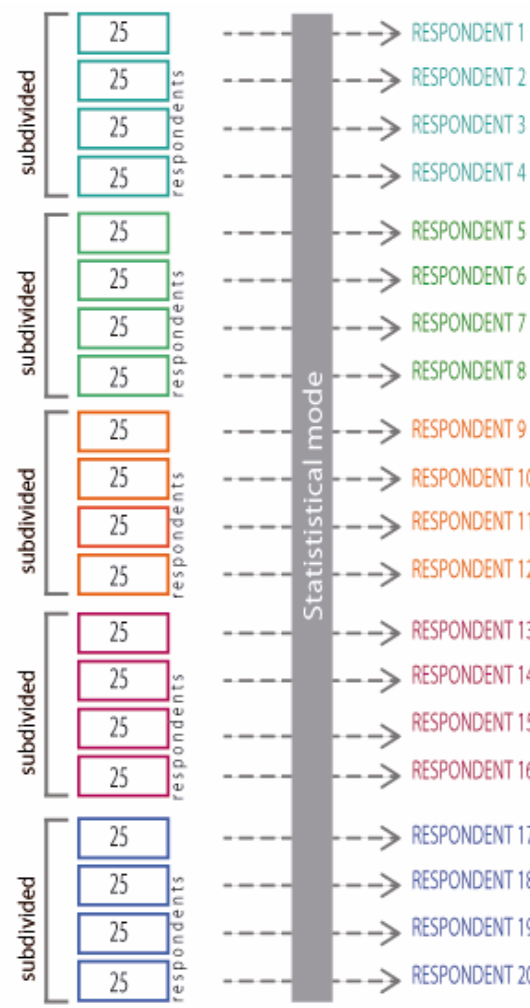

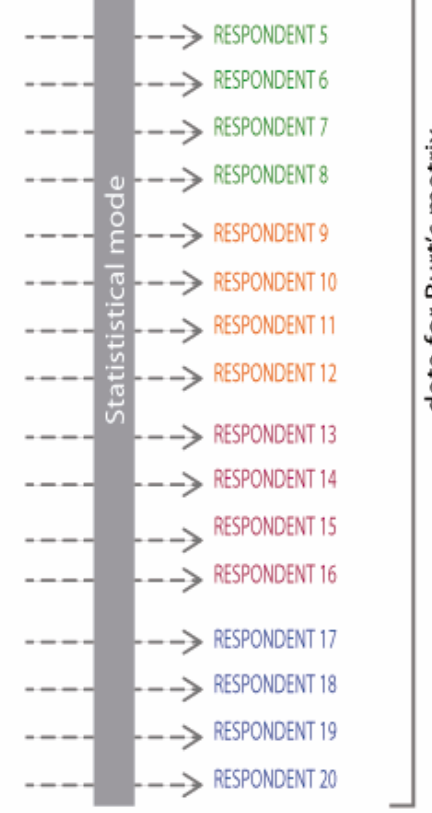

*NOTE: The data of Inquirier number 1 were discarded due to the lack of reliability of data.

Figure 1: From 500 questionnaires 100 were applied by each inquirer and subdivided into four groups. Also, a statistical mode was used to obtain the number of respondents required for the Burt's matrix. (Source: Author.)

\section{RESULTS}

The results of the survey showed the following opinions in item number one: Under your point of view What is the main foreign architectural influence on industrial sites in Aguascalientes? Some of the students mentioned types of materials used in factories and houses and the way factories used to function. They also recognized architectural influences brought from Europe and from the United States, but also England had to do with it 
because the first factories were first established in that country. But also, functionalism shaped some industries during the 20th century. Materials and double shed roofs also came to Mexico to be used in a lot of factories, and in some cases Art Deco was used in some other factories.

The answers for the second item: Explain briefly how social interaction was inside industrial heritage of Aguascalientes, showed significance results. Some mentioned communities of workers settled down near the factories. In the case of the railway company in Aguascalientes, numerous residences were designed as housing for workers near the train station and the railway workshops.

About the third item: Can you identify architectural typologies of industrial heritage? The answers were related to materials, architectural styles and types of spaces. But also, some answers were associated to horizontal windows, the use of glass and concrete in several industrial buildings from the 20th century.

The fourth item's main goal was to explain how changes in land use influenced in industrial sites. Basically, thanks to railway and road systems the main cities of Mexico started to grow, and in a lot of cases there were changes from lands devoted to agriculture to lands for cities.

The fifth item asked for an explanation of relevant concepts students knew about industrial heritage. Taylorism was detected in some of the answers. Also, the concept of reversibility, which was frequently, used in contemporary restoration works. And finally industrial heritage - related to preservation of unique buildings. Yomna says: Over the course of history, architecture played an important role in manifesting the identities of cities; as each era had its unique architecture that represents the culture and ideologies of people, as well as their values and traditions [2], and industrial heritage is one of them.

The results of the questionnaire applied were concentrated on a matrix. Then a Burt's Matrix was used to apply a qualitative multivariate analysis. A correspondence analysis was the best option to study the results. A complete explanation about how to use this method can be consulted in the author's paper: Urban mobility and qualitative research in historic places [3]. The results of the Burt's matrix for this paper can be observed in Table 1. About the concept of industrial heritage, only $45 \%$ said they understood the meaning of it, but as a contrast $90 \%$ said they could recognize Ferronales suburb. The answers of people about their preferences for Ferronales architecture were: $75 \%$ preferred the tree lined streets and $25 \%$ porches. Also, wood windows were preferred $(100 \%)$ over some other materials. All inquired people considered that industrial heritage was valuable and should be preserved. So, it is important to start working with preservation of the built legacy. Caroupapoullé mentions that the contribution to knowledge is the design and development of a research-led strategic framework for the future development of World Heritage Sites that develops current theories and methods [4]. Also, city planning can contribute a lot with it.

Likewise, $100 \%$ of the people inquired said the place was appreciated for local culture. Also, they all agreed industrial heritage contributed to local landscape architecture. But still there is work to do about preservation of original typologies and to recognize successful actions done in some other historic sites. For example, Broseta suggests improving the management of protection and urban renewal of historic districts: disseminating the good examples and practices in preservation and refurbishment, including digitalization, regarding typologies and constructive techniques [5], which is a respectable point of view.

The last question was also very interesting because it referred to the "breath of the place". The idea was to detect reminiscences and memories of the people about significant 
Table 1: Final Burt's matrix of data obtained from the results of the inquiries.

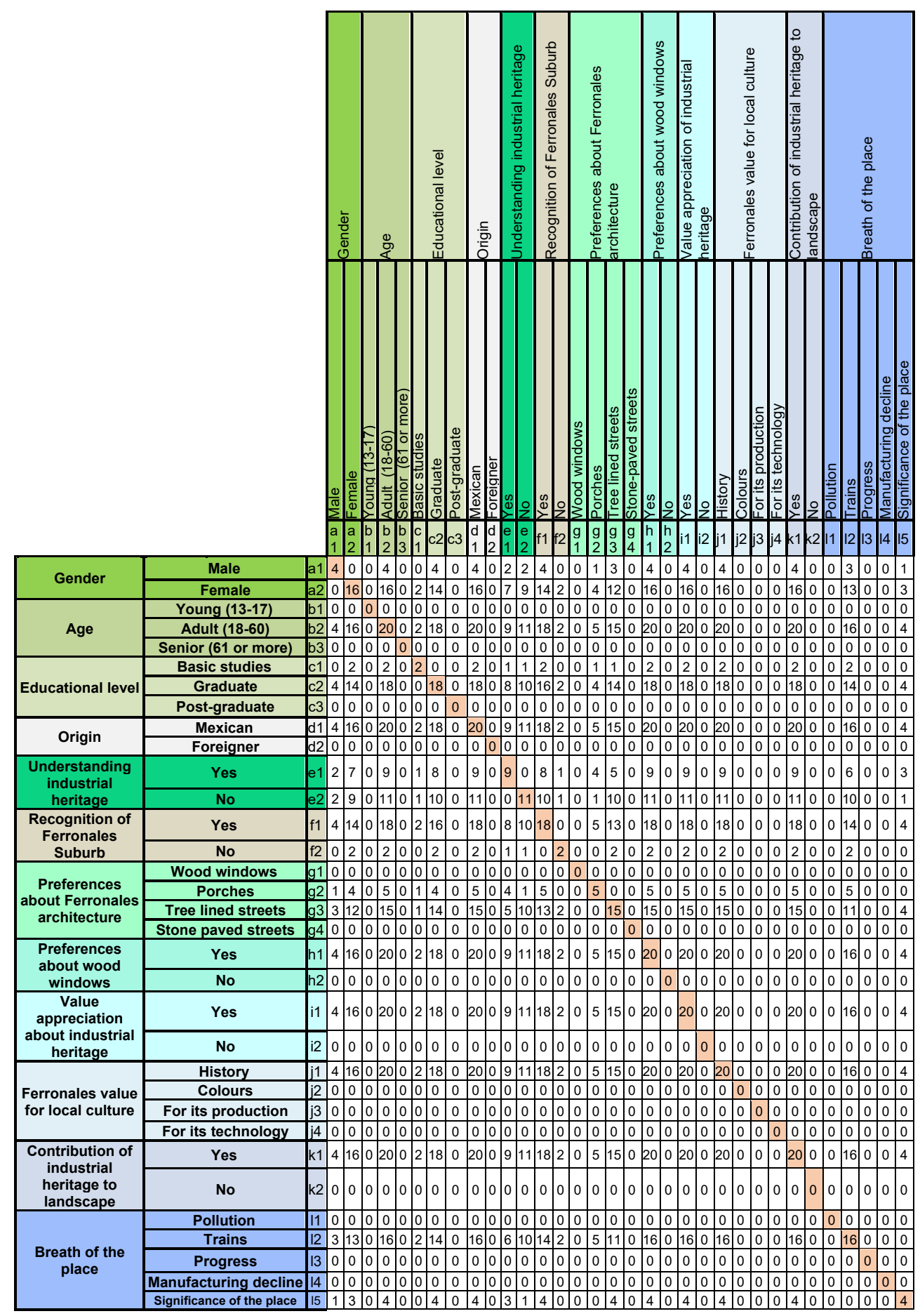


facts of the place. In this case, $80 \%$ of the inquired people answered trains and its sounds were remarkable, and only $20 \%$ mentioned a notable significance of the place for the city.

It is convenient to mention that all the inquired people were adult people, between 18 and 60 years old. This occurred because the questionnaire was applied on line due to the national emergency caused by COVID-19. Under normal circumstances, inquirers could have applied the questionnaires on a square or a park (for example), or some other place, but inquiring any type of people they encountered.

\section{DISCUSSION}

A multivariate analysis is very helpful as a qualitative method. Some variables are crossed with facts that help researchers make significant deductions. Even though the inquirers were young people (from 18 to 22 years old) in this case, the results show most of the inquired people were students from several universities (90\%). But this doesn't mean they completely understood the concept of industrial heritage, so only $50 \%$ affirmed they knew something about it. Likewise, university students preferred urban facts about the historic site, like the tree lined streets. Indeed, such students considered the site worthwhile to live at.

Understanding industrial heritage has to do with a strong recognition of Ferronales suburb, also in the cases mentioned in this paper. This is helpful in order to promote an entire typological record to encourage preservation of the historic site. This means most educated people agree with preservation of historic architecture and urban contexts. Also, they agree historic architecture has important values and contributes to local culture and landscape.

Referring to origin of the inquirers, they were basically Mexican. Even though the Ferronales suburb has railway houses with a typical American style, no Americans live in the place anymore. It can be found in historical archives of Aguascalientes that first owners of Ferronales houses were Americans, but they decided to move away from Ferronales due to railway enterprise problems. This situation happened more than 100 years ago.

Also, an interesting relationship between preferences about Ferronales architecture (tree lined streets) and contribution of industrial heritage to landscape demonstrates that nature could be part of historic sites, and sustainable city designers can help with this type of integration. In fact, the tree-lined streets with a combination of historic one-story houses make Ferronales suburb a unique place to live in Aguascalientes.

There's also a combination of factors that show an interesting relationship between Ferronales value for local culture with preferences about wood windows. In Aguascalientes almost anybody uses wood windows in houses nowadays. It looks like such construction material became out of use through the times. So, young people relate the artefact (wood windows) to their imaginaries about historic houses.

Finally, another interesting inference has to do with the concept of industrial heritage and its relationship with some types of buildings. During the last two decades this concept has been developed and some countries from Europe are very interested in recovering architecture from industrial revolution phases, especially Spain and England. In Latin America, some governments and academics are concern about preservation of this type of architecture, mainly from the second phase of industrial revolution. This was from 1870, at the time invention of electricity made possible assembly lines in factories, to 1969, right when programmable controllers changed production lines. During this phase, good architecture was built - related to industry - including housing for workers, which is the basic issue of this paper. At the end, not a lot of people are concerned about preservation of 
industrial heritage, but there is good expectation people will understand this type of heritage during the next years.

\section{CONCLUSIONS}

Windows and entrances arrangement have to do with proportions. Somehow window arrangement has contributed to improve exterior perspectives in historic sites. If someone takes a look at windows and entrances in Carranza Street in Aguascalientes City, it can be observed that dimensions are variable. In the case of religious buildings (Figs 2 and 3), opening 1, 17 and 21 show a proportion of 1:2; in fact they are the biggest openings. Also, the south city block facing shows several big openings but they are related to newer architecture and altered historic buildings. In addition, intermediate size can be classified with openings $6,8,30$ with a proportion of $1: 1.5$, also openings 11,28 and 38 with a proportion of 1:2. Moreover, the opening 28 correspond to a religious building. The opening 41 has an intermediate size, but keeps a proportion of 1:1.

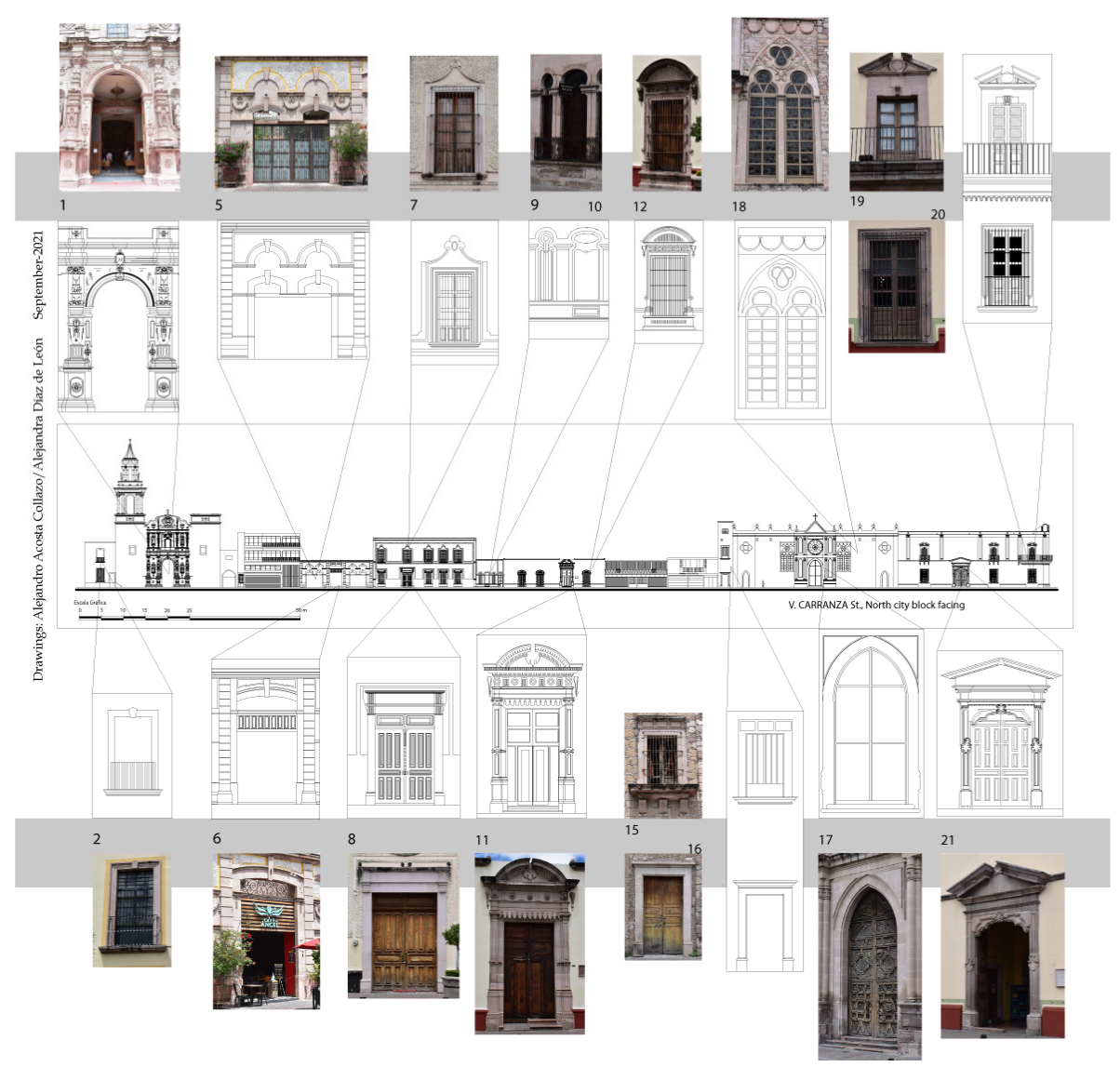

Figure 2: Typology of Carranza St. openings (windows and entrances, north city block facing). (Source: Author's research, 2021. Drawing made and edited by Alejandro Acosta Collazo and Alejandra Díaz de León Esparza. Photographs by Jéssica González Reyes, September 14th 2021.) 


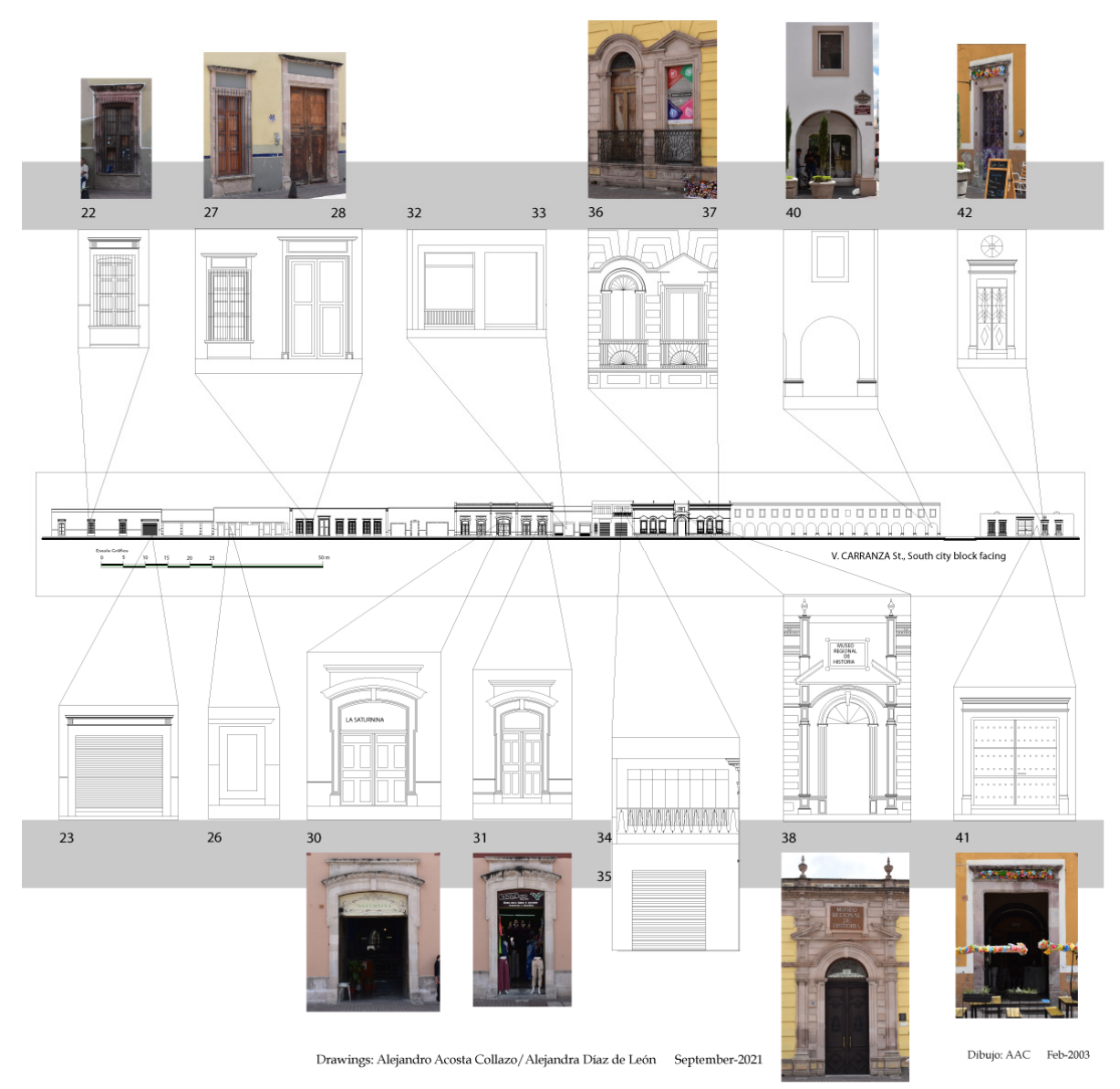

Figure 3: Typology of Carranza St. openings (windows and entrances, south city block facing). (Source: Author's research, 2021. Drawing made and edited by Alejandro Acosta Collazo and Alejandra Díaz de León Esparza. Photographs by Jéssica González Reyes, September 14th 2021.)

The most common openings are the small ones. This is the situation of openings 2, 7 , $10,12,20,22,27,31$ and 42. Actually, they keep a proportion of 1:2 (see Figs 2 and 3). Another classification for these small openings is the proportion 1:3, especially in openings 18,19 and 36. Also, it is possible to identify small openings with a proportion of 1:2.5 (see opening 37 in Fig. 3). One opening with a proportion of 1:1.5 (opening 15) was found and another opening with a proportion of 1:4 (see opening 9 in Fig. 2) was also found.

Openings of main facades of historic buildings sometimes change because of commercial stores or businesses. They rent them, remodel their spaces and remove walls or structures. The reason of choosing these city blocks was because in the whole city centre they have a high concentration of historic and unique buildings (including houses). Even though the street is considered a World Heritage Site, several transformations on windows and entrances have occurred, as a consequence the proportion of such openings have 


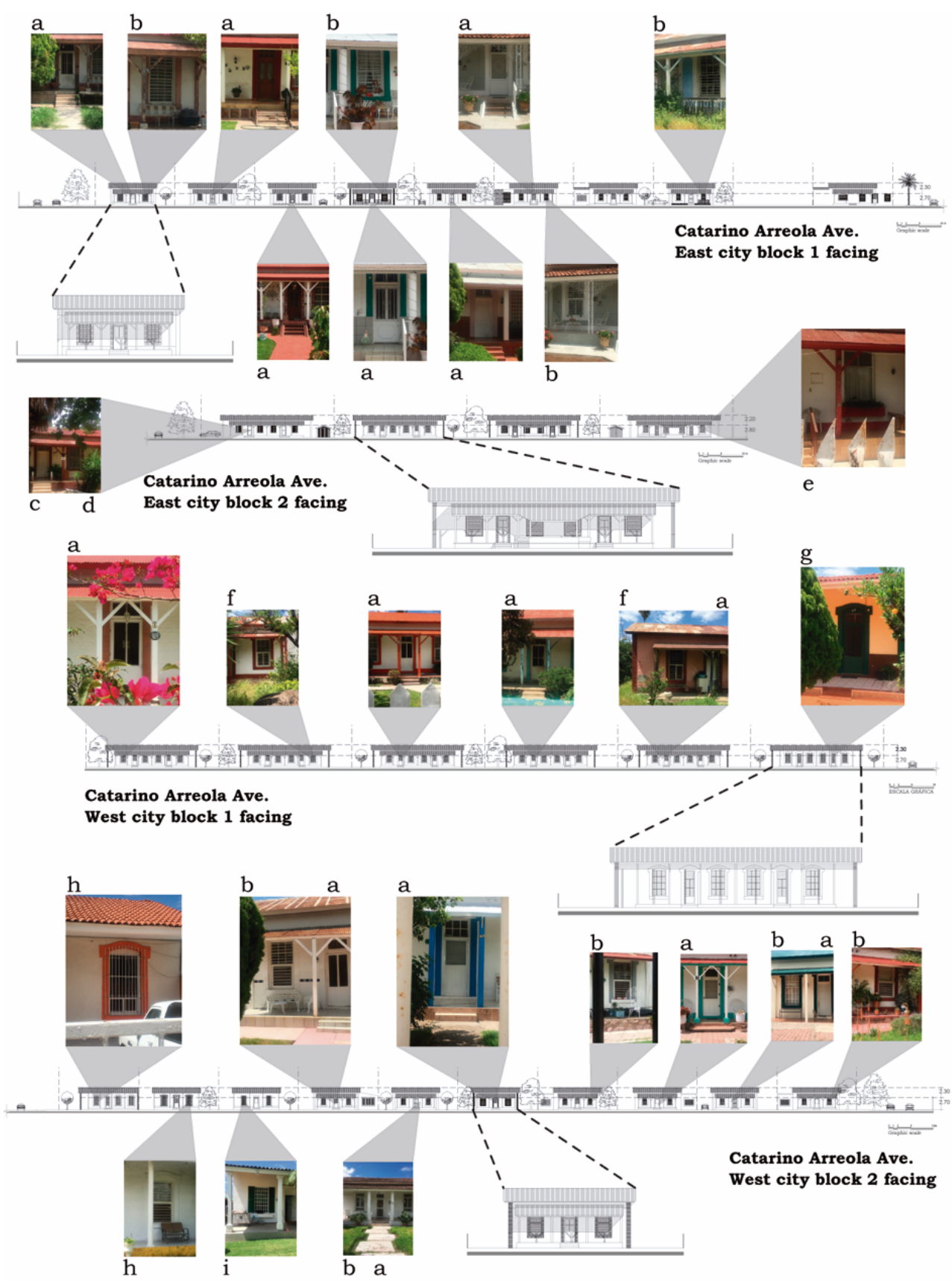

Figure 4: Typology of Ferronales suburb. Catarino Arreola Ave. openings (windows and entrances). (Source: Author's research, 2021. Drawing made and edited by Alejandro Acosta Collazo and Fernanda Pérez Sifuentes. Photographs by Carmen Paulina Muñoz Rangel, September 19th 2021.) 
changed from a vertical position to a horizontal position, especially during the second half of the 20th century.

In Ferronales suburb, the analysis of the place and typologies demonstrated that Aguascalientes red bricks and limestone were used to shape entrances and windows. In Fig. 4 it can be observed that typologies differ in measures, but they all have vertical shapes. Dimensions of typologies are as follow: (a) $1.40 \times 2.15 \mathrm{~m}$ (15 entrances), (b) $1.40 \times 1.75 \mathrm{~m}$ (eight windows), (c) $1.14 \times 2.25$ (one entrance), (d) $1.44 \times 1.72$ (one entrance), (e) $1.60 \times$ $1.95 \mathrm{~m}$ (one window), (f) $1.60 \times 1.85 \mathrm{~m}$ (two windows), (g) $1.40 \times 3.22 \mathrm{~m}$ (one entrance), (h) $1.60 \times 2.80 \mathrm{~m}$ (one window), and (i) $1.40 \times 2.34 \mathrm{~m}$ (one window). It can be observed that the most common entrance is (a) with a proportion of $1: 1.5$, and also, the most common window is (b) with a proportion of 1:1.25.

Nowadays, they are building a cinema complex too close to Ferronales suburb, so inhabitants are concerned about possible land use changes and the consequences of building parking lots nearby. This situation may affect the original houses for workers and may change dramatically the typical typologies. Government administrators and social actors should understand that preservation of historic sites could be instrumental in rising cultural distinctiveness.

\section{ACKNOWLEDGEMENTS}

I would like to thank my research assistant: Arq. Fernanda Pérez Sifuentes, and also the architecture students: Jéssica González Reyes, Carmen Paulina Muñoz Rangel, Daniela Ruiz Alba, Alejandra Díaz de León Esparza, Amanda Adahí Bribiesca Rocha, Maritza Guadalupe Vázquez Rodríguez, Lluvia del Rocío López Gutiérrez, Xitlalli Rubio Murillo, Javier Alejandro Ruvalcaba Olmos and Ana Paula Santacruz Loera. Appreciation is extended to my friend and researcher: Dr. Marco Alejandro Sifuentes Solís.

\section{REFERENCES}

[1] Kubler, G., The Shape of Time: Remarks on the History of Things, Yale University Press: New Haven, CT, p. 83, [1962] Sixth Printing 1970.

[2] Yasser Fahmy, Y., Mamdouh Nassar, D. \& Tarek Elsayad, Z., Identifying the evolution of cities' architectural characters in connection to global events over time. WIT Transactions on Ecology and the Environment, vol. 249, WIT Press: Southampton and Boston, pp. 127-137, 2020. DOI: 10.2495/sc200111.

[3] Acosta Collazo, A., Urban mobility and qualitative research in historic places. WIT Transactions on the Built Environment, vol. 182, WIT Press: Southampton and Boston, pp. 267-283, 2019. DOI: 10.2495/ut180251.

[4] Caroupapoullé, A., Creating balance between transformation and preservation within UNESCO World Heritage Sites: A case study of Belper, UK. WIT Transactions on Ecology and the Environment, vol. 238, WIT Press: Southampton and Boston, pp. 395-405, 2019. DOI: 10.2495/sc190351.

[5] Broseta Palanca, M.T. \& Pérez Merino, B., Urban regeneration in heritage conservation areas: Culture as a tool of enhancement. WIT Transactions on Ecology and the Environment, vol. 238, WIT Press: Southampton and Boston, p. 416, 2019. DOI: $10.2495 / \mathrm{sc} 190361$. 